\title{
On a small collection of Reduviidae (Insecta: Heteroptera) from Brazil'
}

\author{
Jenero Maldonado-Capriles
}

\begin{abstract}
Ghilianella (Ploeodonyx) australis new species, Empicoris armatus brasilensis new subspecies, and Panamia brasilensis new species are described from Brazil. Five species, previously known from Brazil, are briefly discussed.
\end{abstract}

\section{RESUMEN}

Se describen del Brasil los nuevos taxones Ghilianella (Ploeodonyx) ausfralis, Empicoris armafus brasilensis y Panamia brasilensis. Se mencionan otras cinco especies ya previamente registradas de Brasil.

\section{INTRODUCTION}

Dr. T. J. Henry, from the National Museum of Natural History (NMNH), Washington, D.C., sent me a small collection of Brazilian Reduviidae for identification. The specimens were collected by him or together with Mr. S. P. Fiuza F. Three new taxons were found among them. The holotypes are deposited in the NMNH, other specimens in the NMNH and my collection (JMC) as indicated. The previously know species in the lot may add new locality records. The distributional records for the emesines were taken mostly from Wygodzinsky ${ }^{3}$ and for Phorastes from van Doesburg, $\mathrm{Jr}^{4}{ }^{4}$ Measurements are given in $\mathrm{mm}$.

\section{Reduviidae \\ Emesinae}

Empicoris armatus brasilensis Maldonado, new subspecies.

Male - brownish. Pronotum: lateral carina complete, ivory white; two moderately defined dorsal vittae that do not extend in front to constriction or to hind margin; posterior margin ivory white, short around the

'Manuscript submitted to Editorial Board 13 June 1990.

${ }^{2}$ Department of Crop Protection, Ad honorem. Home address: Urb. Aponte 6-I 1, Cayey, Puerto Rico, 00736.

Wygodzinsky, P., 1966 A monograph of the Emesinae (Reduviidae, Hemiptera). Bull. Am. Mus. Nat. Hist. 133: 1-614.

4van Doseburg, P. H., 1981. Nomenclature in the genus Phorastes Kirkaldy, 1900 (Heteroptera: Reduviidae: Peiratinae). Entomol. Berit. 41: 183-85. 
median concavity of the hind margin and subtriangular in outline laterad of the longitudinal vittae (fig 7); before whitish posterior margin a relatively broad biarcuate brownish band that in its center includes the premarginal tubercle and extends laterally past the apices of discal vittae. Pronotum dorsally, laterally and ventrally with rows of silvery scale-like setae. Antennae stramineous; first segment annulated with black. Fore legs stramineous, annulated with brown; coxae with short postbasal and longer preapical bands; femur with five annuli, the apical the longest; tibiae with three annuli, the middle one much longer than the other two; tarsi with brownish apical half. Middle and hind legs yellowish-white, with many short black annuli on all segments. Fore wings slightly surpassing apex of abdomen; totally covered with numerous uniformly grayish areas as in the nominate form; hind wings hyaline, apex with small blackish area, not spotted. Spiracles whitish; last three connexival margins partly whitish, the distribution of white on the margins differs in all specimens.

Head: length 0.6 , width across eyes 0.55 , width of posterior lobe behind eyes 0.36 . Pronotum tuberculate at middle before apical margin, tubercle tapering to round apex, smaller than in the nominate form; width at humeral angles 0.55 ; hind margin concave medianly (fig 7). Scutellum and metanotum spined. Length of segments of fore legs: coxa 0.7 , femur 1.35 , tibia 1.0 , tarsi 0.2 . Spines on fore femur of uniform length, much shorter than diameter of segment. Pilosity of abdominal sterna uniformly distributed, no bare areas. Genitalia: apical hypopygial spine horizontal, details as in figures 4 to 6 .

Female - paler than male; color pattern similar, diffuse. Shape and dimensions much as in male. Length of body to apex of wings $5.3 \mathrm{~mm}$.

Holotype - male, BRAZIL, Viçose, Minas Gerais, 1 Oct.- 13 Nov. 1985, T. J. Henry and S. P. Fiuza F. collectors; in NMNH. Five paratypes of both sexes, same collection data, three in NMNH, two in JMC.

The above description is practically an expansion of that of the nominate form, Empicoris a. armatus. The differences in measurements between both forms are in tenths of a $\mathrm{mm}$, and the color pattern is similar (fig 7). The male external genitalia of both are smallex in conformation; the shape of the claspers and the hypopygial spine differ (fig. 1 to 3 and 4 to 6). The nominate subspecies is found in northern South America, from the Guianas to Panama, the type locality, and Mexico. It is also found in Cuba and Puerto Rico. I prefer to call the Brazilian specimens a subspecies taking in consideration the very close similarity between adults and the great distance between the type localities. The differences in the external genitalia is something to be expected considering the isolation of the gene pools. Intermediate forms probably will be collected 

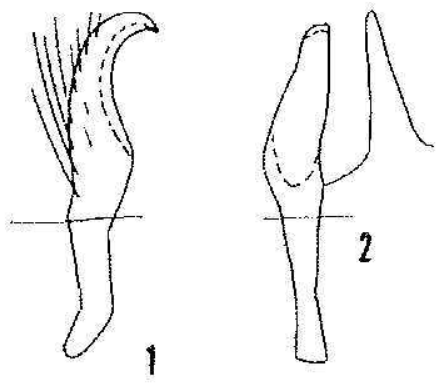

7
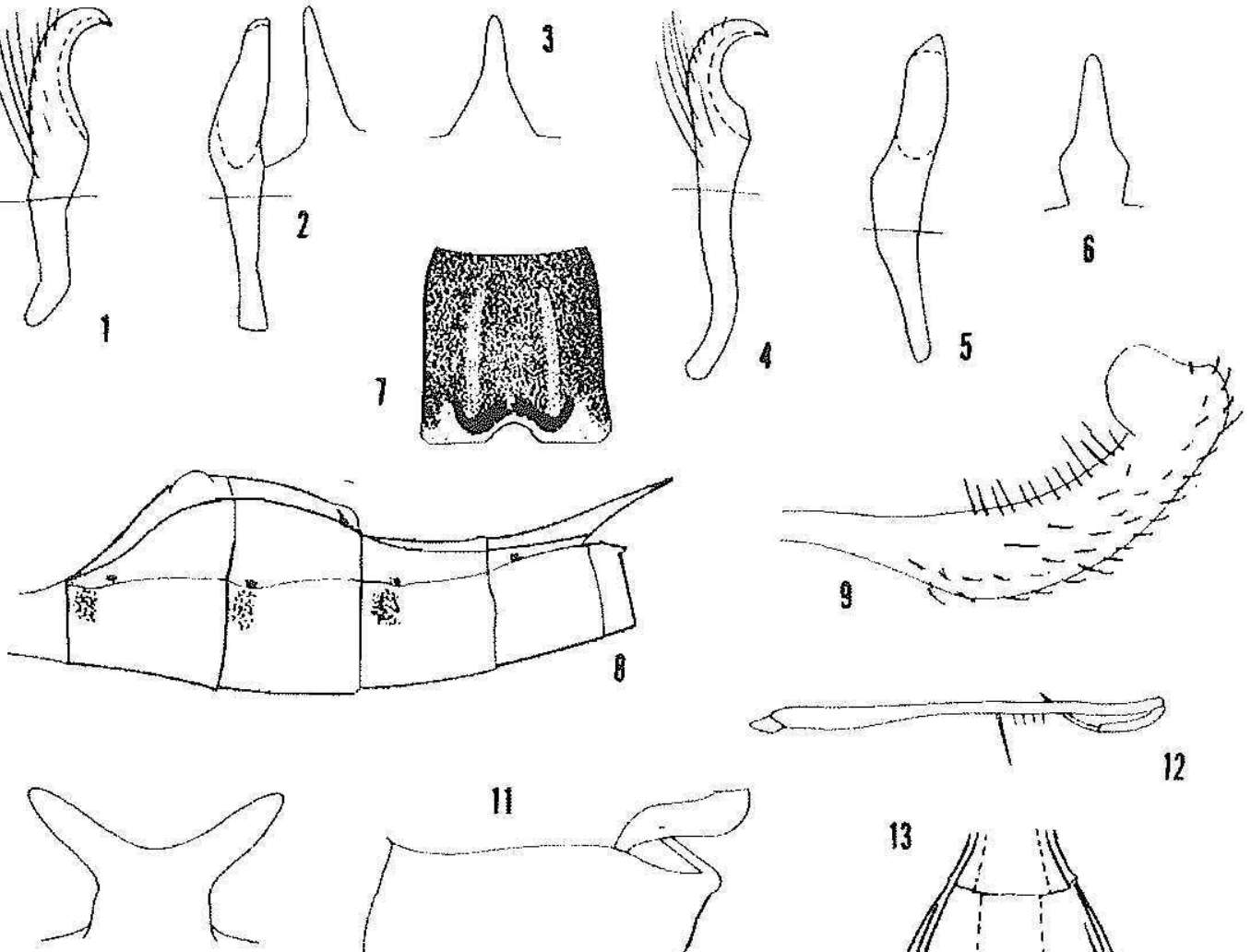

10

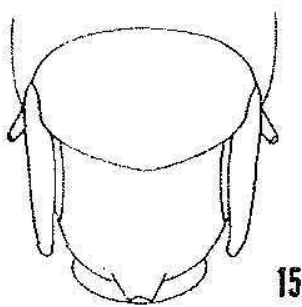

15

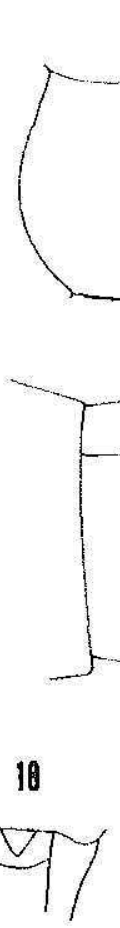

11

11

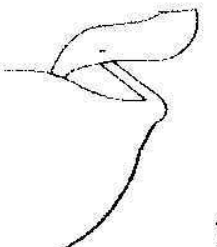

14
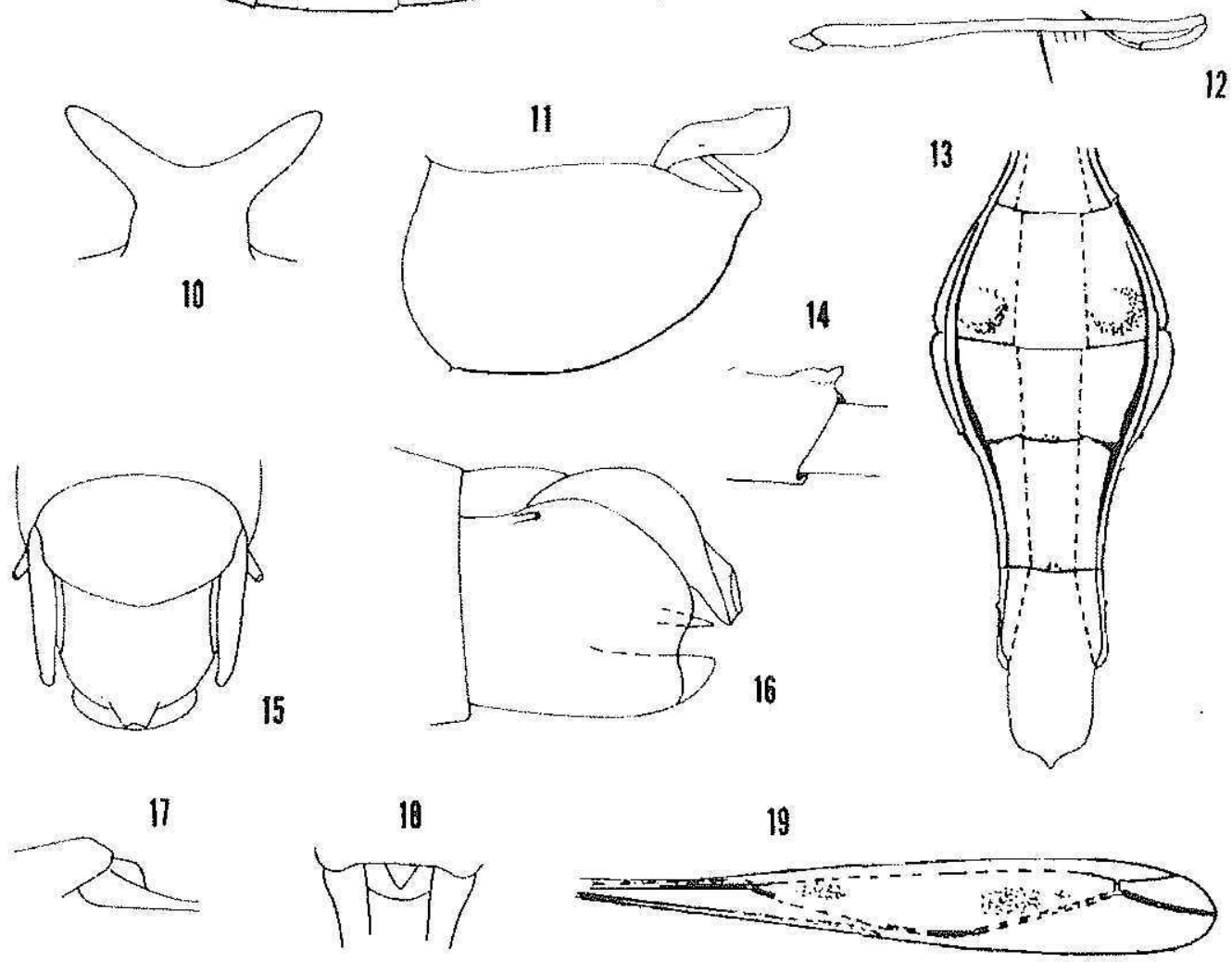

Plate 1-Empicoris armatus armatus, male from Panama, 1. paramere, dorsal; 2. paramere and apical hypopygial spine, lateral; 3. hypopygial spine, dorsal. Empicoris $a$. brasilensis, male holotype; 4. paramere, dorsal; 5. paramere, lateral; 6 . hypopygial tubercle, dorsal; 7. posterior lobe of pronotum, dorsal. Ghilianella (Ploeodonyx) australis, male holotype; 8. abdomen, lateral; 9. paramere, dorsal; 10. apical hypopygial tubercle, caudal; 11. hypopygium, lateral; 12. profemur and tibia, lateral; 13. abdomen, dorsal; 14. apical spines of anterior lobe of pronotum. Panamia brasilensis, female holotype; 15 . genital segments, dorsal; 16. genital segments, lateral; 17. scutellum in place, lateral; 18. scutellum in place, dorsal; 19. fore wing. 
between the type localities. Drawings of the genitalia of the nominate species are from a Panamanian specimen. Grillo and Alayo's Empicoris soroanus and $E$. cubanus from Cuba, especially the first, are close to $E$. armatus. All have an elongate, horizontal hypopygial spine that differs slightly in the shape of their respective bases. The general shape of the parameres of the three species is similar but differs in details; e. g., their base is cylindrical and the apical half or third is scooped; the length of the scooped part differs in the species and the subspecies. The fore wings are similarly colored. Both Cuban species have black spots on the apex of the hind wings whereas both subspecies of $E$. armatus have a small blackish area.

Empicoris mubromaculatus (Blackburn): specimens from Viçosa, Minas Gerais; Amazonas, Manaus; Quinta da Boa Vista, Rio de Janeiro; San Jose de Pinhais, Paraná. A cosmopolitan species; in America found from Brazil to western United States and the Antilles.

Gardena faustina McAtee \& Malloch: one male from Amazonas, Manaus. Known from Central America to Brazil.

Gardena pipara McAtee \& Malloch: Viçosa, Minas Gerais. Known from Brazil, Bolivia, Paraguay and Argentina.

Ghinallelia minimula (McAtee \& Malloch): Viçosa, Minas Gerais. Findemic to Brazil.

Ghilianella (Ploeodonyx) australis Maldonado, n. sp.

Figs 8 to 14

Male - black. Second and third abdominal segments pale brownish; areas and lines of yellowish-white scale-like setae as follows: narrow longitudinal lines on anterior lobe of head, broader irregular rows on posterior lobe of head, anteriorly on pronotum, posterior end of mesonotum, anteriorly and posteriorly on mesonotum, above on middle and hind coxae, two very pale basal dashes on abdominal terga 3 to 6 , and semicircular areas cephalad to spiracles on sterna 4 to 6 (fig. 8); VII sternum mostly yellowish brown.

Head: length 2.4, width across eyes 1.1, interocular space 0.5 ; eyes of medium size, not reaching upper or lower margins of head, produced laterally, interantennal spine slightly downcurved. First antennal segment 9.7. Rostrum: I, 0.5; II, 0.6; III, 1.2. Pronotum - lobes: 3.6, 3.6, 2.1 ; anterior lobe with a pair of elongate dorsal tubercles on posterior margin (fig. 14). Anterior legs: Coxae 4.5; femur 6.9, constricted to be-

${ }^{5} \mathrm{Grillo}$, H. y P. Alayo, D., 1979. La subfamilia Emesinae (Heteroptera: Reduviidae) en Cuba. Centro Agricola, Sept.-Dic., pp, 51-88. 
fore first spine (fig. 12), first spine 0.6 long, at 3.7 from base; tibia 1.4; tarsi 2.2; one claw, not totally fused to tarsus. Abdomen (fig. 13) with bulbous swelling; slightly and gradually expanding to apex of third segment, fourth segment expanded and forming basal half of swelling, with large hemispherical elevation before each apical angle of tergum; fifth segment forming apical half of swelling, each apical angle of tergum raised above surface of sixth tergum; sixth tergum nearly as long as wide basally (1.2:1.25), narrower apically (1.1); seventh tergum with apical half narrower than basal half, apex almost reaching apex of hypopygium; middle apical margin of terga 2 to 6 without wart-like granule and lateral angles not projected laterally, terga 4 and 5 inside connexival margins, posterior margin of sterna 7 and 8 straight (fig. 8). Details of the genitalia as in figures 9 to 11 . Length of body $21.5 \mathrm{~mm}$.

Holotype - male, BRAZIL, Amazonas, Manaus, at the Instituto de Pesquisas Amazonia (INPA), 27 Nov.-8 Dec., T. J. Henry collector, in NMNH.

Subgenus Ploeodonyx is characterized by a slender fore femur, notably thinner before first strong spine than basally (fig. 12). Ghilianella australis is characterized by the bulbous abdominal swelling, the yellowish areas before spiracles on sterna 4 to 6 , characters that do not occur in the other four species in the subgenus. The process of the apical margin of the hypopygium is inclined cephalad (fig. 11) and Y-shaped (fig. 10). It is similar to that of Ghilianella (Ploeodonyx) insidiatrix. G. australis extends quite south the geographic distribution of the subgenus. It was known only from the Guianas and the Windward Islands of the Lesser Antilles.

Panamia brasilensis Maldonado, new species

Figs. 15 to 19

Female - mostly yellowish. Head brownish, posterior lobe paler, beneath and first segment of rostrum as dark as anterior lobe of head. Anterior lobe of pronotum pale brownish (brownish in paratype), with $1+1$ inconspicuous longitudinal bracket shaped stripes; posterior lobe yellowish. Scutellum yellowish, unmarked. Hemelytra (fig. 19) yellowish white, veins deeper yellow, one smaller oval light bluish-gray area near base and one larger deeper colored near apex of discal cell; a brownish line laterad to $\mathrm{M}+\mathrm{Cu}$; base of $\mathrm{PCU}+1 \mathrm{~A}$ vein brownish; slightly surpassing apex of abdomen. Fore tibia inconspicuously banded with light brown at midlength. Abdominal sterna irregularly variegated with brownish.

Head - length 0.7 , width across eyes 0.51 , from apex of head to interocular suture 0.4, from interocular suture to base 0.3 , interocular space 1.5; eyes large as seen from above, reaching upper but not lower 
margin of head, slanted on lateral aspect. Rostrum: I, 2.5; II, 2.5; III, 3.5; last segment slightly upcurved, glabrous. Antennal segments: I, 2.5; II, 2.4; III and IV missing; glabrous. Pronotum: anterior lobe polished, $0.35 \mathrm{long}$, slightly wider posteriorly than anteriorly $(0.55: 0.45)$, the pronotum seems to be wider anteriorly as the acetabula are visible from above; posterior lobe very finely and densely punctate, length 0.95 , width at humeral angles 1.0 , width at middle constriction 0.62 ; humeral angles roundly projected caudad of posterior margin; scutellum horizontal, as in figures 17 and 18, 0.15 long. Foreleg: coxa 1.0, trochanter 0.25, femur 1.7, tibia 1.2. Armature of fore femur with 4 or 5 spinules, finely denticulate, and with abundant short pilosity. Genital segments as in figures 15 and 16.

Holotype female - BRAZIL, Amazonas, Manaus, at the Instituto de Pesquisas de Amazonia (INPA), 27 Nov. -8 Dec., 1985, T. J. Henry collector. Paratype female - Brazil, Amazonas, $37 \mathrm{~km}$ N of Manaus, Manaus-Carcari Rd, Dec. 3, 1985, T. J. Henry collector, in JMC. Unfortunately the abdomens of both specimens were destroyed by psocids after they were described and illustrated.

The American Ploiariolini genera Panamia and Malacopus are very close including an almost exactly similar fore wing venation. The scutellum of the first is unspined. Panamia ornata (Champion) is the only other species and also known from females only. This species was profusely illustrated by Wygodzinsky3. It has many small spots on the diseal and apical cells of the hemelytra, the scutellum is humped and probably wider than long, and the external female genitalia show significant differences from that of the new species. Wygodzinsky's figure 122-R of the dorsal genitalia shows an incomplete eighth tergum. This sclerite is complete in $P$. brasilensis. Until males become available the affinities of this genus will remain unsettled.

Peiratinae

Phorastes femoratus (Degeer): Vicosa, Minas Gerais.

This colorful species is known from Brazil, Surinam, and Argentina. 